\title{
INTERNALISASI NILAI TAWAKAL PADA SANTRI DI PONDOK PESANTREN BADRUL ULUM AL-ISLAMI PACET - KABUPATEN BANDUNG
}

\author{
Pupu Fakhrurrozi,* Aceng Kosasih, Fahrudin \\ Universitas Pendidikan Indonesia \\ *Email:fakhrurrozi1992@gmail.com
}

\begin{abstract}
This research was conducted in Pondok Pesantren Badrul Ulum Al-Islami al-Salaf Islamic boarding school which was founded in 1918 and still exists until now. The method used in this research is descriptive method with qualitative approach and literature study. The result obtained from this research are: The goal of internalization of tawakal value with zikr ya wakil is for clearing the soul (saffat asrarubu). Internalization process of tawakal value, among others, applied in the activity of congregation of riker, learning activity, and daily activity. The result of the internalization of the value of tawakal is that the person will have a bappy feeling. The obstacles of in the process of internalization are no thorough awareness of the internalization of tawakal value, the existence of takhassus student under the age of high scholl, and the lack of cohesiveness amongst students in order to belp to maximaze pondok pesantren's program.
\end{abstract}

Keyword:Internalization, value, tawakal, PondokPesantren

\begin{abstract}
ABSTRAK
Penelitian ini di laksanakan di Pondok Pesantren Badrul Ulum Al-Islami sebagai pesantren salaf yang di dirikan pada tabun 1918 dan masib eksis hingga sekarang. Metode yang digunakan dalam penelitian ini yaitu metode deskriptif dengan pendekatan kualitatif serta ditunjang oleh studi kepustakaan. Hasil yang diperoleh dari penelitian ini yaitu: Tujuan internalisasi nilai tawakal denganzikir yä wakil adalah agar hati jernih (Ṣaffat asrärubu). Proses internalisasi nilai tawakal diantaranya diterapkan dalam aktivitas zikir berjamaah, kegiatan pengajian, dan aktivitas keseharian. Hasil internalisasi nilai tawakal adalah bahwa orang yang sudah bertawakal akan mempunyai perasaan bahagia. Hambatannya adalah belum begitu menyelurubnya kesadaran mengenai internalisasi nilai tawakal, adanya santri takhassus di bawah usia SMA, serta kurangnya kekompakan sesama kepengurusan santri dalam rangka membantu memaksimalkan program kepesantrenan.
\end{abstract}

Kata kunci: Internalisasinilai, Tawakal, Pondok Pesantren. 


\section{PENDAHULUAN}

Dekadensi moral menjadi satu hal yang hangat diperbincangan saat ini. Hal ini karena fenomena dekadensi moral selalu disuguhkan dengan begitu dahsyat. Dalam rusaknya akhlak, dekadensi moral, hancurnya tatanan peradaban, hilangnya perasaan damai, timbulnya kecurigaan dan ketidak percayaan yang berlebihan, penindasan yang kuat kepada yang lemah, meluasnya pembunuhan karakter, berantakan tata nilai kehidupan, korupsi yang merajalela, hilangnya rasa hormat kepada sesama, terjerumus pada lubang kehinaan, lalainya ketaatan beribadah hal ini diindikasikan akibat rusaknya sistem pendidikan (Sauri, 2013:1).

Pendidikan di Indonesia memiliki ketidakseimbangan antara pendidikan akademik, pendidikan akhlak/pendidikan nilai dan pendidikan keterampilan. Dari sudut pendidikan nilai, sebagaimana yang dikehendaki oleh tujuan pendidikan nasional, maka pendidikan di Indonesia dapat dikatakan gagal atau kurang berhasil. Fenomena kegagalan ini misalnya dapat dilihat dari produk pendidikan yang menghasilkan generasi yang kurang hormat pada guru/dosen, orang tua, sering terjadi tawuran, pergaulan bebas, gaya hidup hedonism, kebaratbaratan (meninggalkan budaya bangsa) dalam beberapa hal seperti dalam fashion, musik, makanan dan lain-lainnya (Fahrudin, 2013, p. 6).
Walaupun Indonesia merupakan negara dengan penduduk muslim terbanyak di dunia, pemahaman mengenai makrifat kepada Allah SWT belum tertanam di dalam jiwa setiap muslim Indonesia. Padahal makrifat kepada Allah akan menyucikan jiwa dari sifat buruk, seperti dendam, sum'ah (ingin didengar), riya (ingin dilihat), bubb al-jäb (gila kedudukan), bubb al-māl (gila harta), dan sifat buruk lainnya. Kesucian jiwa akan mendorong seseorang untuk beramal saleh. Sedangkan amal saleh akan menghapus dosa-dosa, dan kemudian Allah akan menggantinya dengan pahala yang berlipat ganda (Affandi, 2008, p. 19).

Untuk mencapai kesucian jiwa yang akan mendorong seseorang untuk beramal saleh diperlukan usaha diantaranya adalah selalu bertawakal kepada Allah SWT. Karena tawakal merupakan salah satu hasil dari iman dan buah dari makrifat. Sejauh mana seorang hamba mengenal Allah SWT dan sifatsifat-Nya, maka sejauh itu pulalah tawakalnya kepada-Nya. Sesungguhnya yang bertawakal kepada Allah SWT hanyalah orang yang tidak melihat adanya pelaku selain Dia. Orang yang bertawakal kepada Allah adalah orang yang bangga dengan-Nya, tidak merasa hina kecuali di hadapan-Nya, percaya sepenuhnya dengan-Nya, dan tidak meminta sesuatu kecuali dari-Nya. Kaum sufi berkata "Buruk bagi seorang murid, meminta sesuatu kepada seorang hamba, padahal dia menemukan semua apa yang diinginkannya pada Tuhannya." (Isa, 2005, p. 263).

Pesantren Badrul Ulum ini menerapkan sistem pengajaran tradisional pengajian al-Qur`an, al-Hadits, kitab 
klasik (kitab kuning) termasuk kitab al-bikeam karya syekh Ibn Ațāillah, dan mengamalkan żikir $Y \bar{a} W a k i l l$. Zikir tersebut diamalkan oleh santri-santri senior setiap malam di masjid pesantren dengan sistem jadwal atau bergantian setiap malamnya. Diamalkan oleh seluruh santri pada setiap malam minggu secara berjamaah. Amalan żikir ini tidak hanya diamalkan oleh santri saja, tetapi juga oleh masyarakat sekitar pesantren, termasuk para alumni. Sehingga baik antara ikatan pesantren dengan alumni maupun masyarakat pada umumnya masih terus terjalin. Hal tersebut membuat peneliti tertarik untuk mengadakan penelitian di pondok pesantren tersebut, dengan mengambil judul "Internalisasi Nilai Tawakal pada Santri di Pondok Pesantren Badrul Ulum AlIslami".

\section{METODE PENELITIAN}

Metode yang digunakan dalam penelitian ini yaitu metode deskriptif dengan pendekatan kualitatif serta ditunjang oleh studi kepustakaan. Menurut Satori (2012: 22) penelitian kualitatif adalah penelitian yang menekankan pada quality atau hal yang terpenting dari sifat suatu barang/jasa. Desain yang digunakanadalahdesaincase study yang bersifat deskriptif, karena bertujuan memaparkan internalisasi nilaitawakalpadasantri di Pondok Pesantren BadrulUlum Al-Islami

Teknik yang digunakan untuk mengumpulkan data yaitu wawancara, pengamatan langsung, dan studi dokumentasi. Teknik analisis data menggunakan teknik deskriptif interpretatif.Menurut Sugiyono (2011:309) dalam penelitian kualitatif, pengumpulan data dilakukan pada natural setting (kondisi yang alamiah), sumber data primer, dan teknik pengumpulan data lebih banyak pada observasi berperanserta (participant observation), wawancara mendalam (in depth interview) dan dokumentasi.

\section{HASIL DAN PEMBAHASAN}

Internalisasi nilai menurut Chabib Thoha dalam (Nashihin, 2015, p. 3) yaitu merupakan teknik dalam pendidikan nilai yang sasarannya adalah sampai pada pemilikan nilai yang menyatu dalam kepribadian dan perilaku peserta didik. Internalisasi diartikan sebagai proses penanaman nilai kedalam jiwa seseorang sehingga nilai tersebut tercermin pada sikap dan prilaku yang ditampakkan dalam kehidupan sehari-hari (menyatu dengan pribadi) (Utomo, 2016, p. 95). Dengan memperbanyak zikir yā wakìl ini harapannya agar nilai ketawakalan dapat terinternalisasi dalam diri setiap santri.

Syekh Abu Nashr as-Sarraj rabimabullāh- (2002, p. 105) berkata bahwa tawakal adalah kedudukan spiritual yang mulia. Allah telah memerintahkan untuk selalu bertawakal dan Dia menjadikannya selalu berbarengan dengan iman. Sebagaimana firman-Nya:

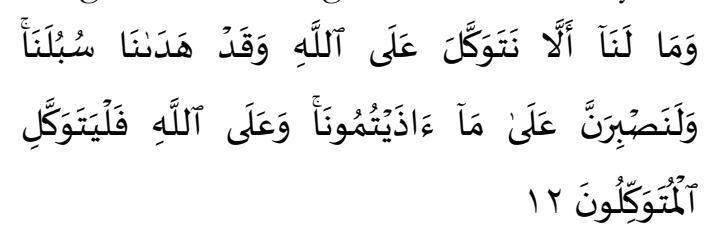

"Mengapa kami tidak akan bertawakkal kepada Allah padahal Dia telah menunjukkan jalan kepada kami, dan kami sungguh-sungguh 
akan bersabar terhadap gangguangangguan yang kamu lakukan kepada kami. Dan hanya kepada Allab saja orang-orang yang bertawakeal itu, berserah diri" (Q.S. Ibrahim [14]: 12).

Kaum sufi telah merumuskan teori-teori tentang jalan menuju Allah, yakni menuju suatu tahap ma'rifat (mengenal Allah dengan hati). Potensi untuk memperoleh ma'rifat sebenarnya telah ada pada manusia. Untuk memperolehnya, hati mempunyai fungsi yang esensial, hati merupakan tempat kedatangan kashf dan ilham. Dalam dunia tasawuf, hati merupakan pengetahuan tentang hakikat, termasuk di dalamnya adalah hakikat ma'rifat. Hati yang dapat memperoleh ma'rifat adalah hati yang telah suci dari berbagai akhlak tercela yang sering dilakukan oleh manusia. Hati menjadi sarana untuk memperoleh ma'rifat. Hatilah yang mampu mengetahui hakikat pengetahuan, karena hati dibekali potensi untuk berinteraksi dengan Tuhan. Ini mengisyaratkan bahwa ma'rifat tidak spontan dimiliki sembarang orang, melainkan hanya dimiliki orang-orang yang telah melakukan upaya-upaya untuk memperjuangkannya. Di samping melalui tahapan maqāmat dan abwāl, untuk memperoleh ma'rifat seseorang harus melalui upayaupaya tertentu, seperti riyạdah. (Hakam, 2014, p. 147).

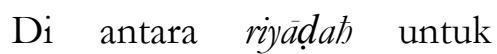
menuju tahap ma'rifat adalah zikir. Asal zikir adalah ash-shafa, artinya bersih dan hening. Wadahnya adalah al-wafa artinya menyempurnakan. Dan syaratnya adalah al-budhur, artinya hadir hati sepenuhnya. Hamparannya adalah amal saleh. Dan khasiatnya adalah pembukaan dari Tuhan Al-Aziz Ar-Rahman. Menurut bahasa, zikir artinya ingat atau sebut. Kalau dalam pengertian ibadah, zikir berarti suatu amal yang disebut berzikir. Jadi zikir Allah atau Dzikrullah artinya ingat kepada Allah atau menyebut Allah. Di dalam al-Qur'an tidak sedikit ayat-ayat yang menyuruh kita mengingat Allah atau menganjurkan orang berzikir dan menyatakan keutamaan zikir Allah. Demikian pula hadits Nabi, atsar sahabat dan tabi'in banyak sekali menyebutkan fadhilah zikir (Abdullah, 2007, p. 82).

Pesantren merupakan lembaga pendidikan yang bertujuan untuk Taffaqub Fiddin (Memahami agama) dan membentuk moralitas umat melalui pendidikan. Sampai sekarang, pesantren pada umumnya bertujuan untuk belajar agama dan mencetak pribadi muslim yang kaffah yang melaksanakan ajaran Islām secara konsisten dalam kehidupan seharihari. Tujuan taffaquh fiddin dan mencetak kepribadian muslim yang kaffah dalam melaksanakan ajaran Islām didasarkan kepada tuntutan Al Qur`ān dan sunnah Nabi SAW. Dimana nabi merupakan top model dan guru imajiner bagi pesantren. Tujuan ini adalah tujuan pokok dalam setiap pesantren yang merupakan lembaga pendidikan Islām tradisional yang teguh menjaga tradisi ulama salaf al shalih dan walisongo yang diyakini bersumber dari Rasūlullāh SAW. Dengan ini maka Islām akan bertahan dan berkembang dalam masyarakat, khususnya di Indonesia. Adapun mengenai tujuan-tujuan khusus, masingmasing pesantren juga mempunyai tujuan 
khusus yang tergantung dengan pengasuhnya (Madjid dalam Suharto, 2011: 11).

Tujuan internalisasi nilai tawakal pada santri di Pondok Pesantren Badrul Ulum Al-Islami ditekankan pada amalan zikir $y \bar{a}$ wakil, agar bertawakal. Karena tawakal itu adalah derajat keyakinan paling tinggi. Tujuan yā wakil agar jernih hati (șaffat asrärubu) karena setelah hati jernih seseorang akan sampai ke hadirat Ilahiyah. Tawakal itu menyerahkan segala urusan kepada Allah SWT setelah kita berusaha semaksimal mungkin. Perjalanan ya wakil ini merupakan perjalanan melalui jamalullah (keindahan Allah, ke-rabman-an Allah). Maka pada amalan yā wakil harus merasa bahagia. Seseorang yang mengamalkan zikir ini harus mengingat berbagai nikmat Allah, sudah diurus oleh Allah, diciptakan oleh Allah, diberi rezeki oleh Allah, dan nikmat-nikmat lainnya.

Tujuaninternalisasinilaitawaka lpadasantriPondokPesantrenBadrul Ulum AlIslamiinisudahsangatsejalandengant ujuanpendidikan Islam sendiri.Tujuan pendidikan Islām menurut Abu Ahmadi (Ramayulis, 2011: 134-143) bahwa tahap-tahap tujuan pendidikan Islām meliputi: tujuan tertinggi/terakhir, tujuan umum, tujuan khusus dan sementara.Tujuan pendidikan yang tertinggi dan terakhir ini pada akhirnya sesuai dengan tujuan hidup manusia, dan peranannya sebagai makhluk ciptaan Allah. Dengan demikian indikator dari insan kamil tersebut adalah menjadi hamba Allah, tujuan ini sejalan dengan tujuan hidup dan penciptaan manusia yaitu semata-mata untuk beribadah kepada Allāh. Dalam hal ini pendidikan harus memungkinkan manusia memahami dan menghayati tentang Tuhannya, mengantarkan subjek didik menjadi khalifah Allähfi al-'Ard, yang mampu memakmurkan bumi dan melestarikannya dan lebih jauh lagi, mewujudkan rahmat bagi alam sekitarnya dan untuk memperoleh kesejahteraan kebahagiaan hidup di dunia dan akhirat. Ciri-ciriinsankamilmenurutNata (2003: 264-267) adalah sebagai berikut:
a. Berfungsi akalnya secara maksimal
b. Berfungsi intuisinya
c. Mampu menciptakan budaya
d. Menghiasi diri dengan sifat-sifat ketuhanan
e. Berakhlak mulia
f. Berjiwa seimbang

Supaya tawakal, maka amal (dzikir) nya adalah yā wakìl, tawakal itu adalah orang yang berpasrah diri secara total kepada Allah, untuk mencapai itu maka harus (mengamalkan) yā wakìl yakni Allah wahai dzat yang mengurus kita, wahai dzat yang menerima penyerahan kita. Sebagaimana terdapat dalam al-Qur'an surat Al-Thalaq [65] : 3

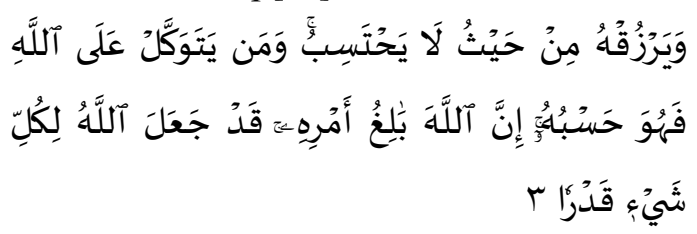

"Hai Nabi, apabila kamu menceraikan isteriisterimu maka hendaklab kamu ceraikan mereka pada waktu mereka dapat (menghadapi) iddabnya (yang wajar) dan bitunglab waktu iddah itu serta bertakwalah kepada Allah 
Tuhanmu. Janganlah kamu keluarkan mereka dari rumah mereka dan janganlah mereka (diizinkan) ke luar kecuali mereka mengerjakan perbuatan keji yang terang. Itulah bukum-bukum Allah dan barangsiapa yang melanggar bukum-bukum Allah, maka sesunggubnya dia telah berbuat zalim terbadap dirinya sendiri. Kamu tidak mengetabui barangkali Allah mengadakan sesudab itu sesuatu hal yang baru."

Proses internalisasi nilai tawakal pada santri di Pondok Pesantren Badrul Ulum Al-Islami diantaranya diterapkan dalam beberapa hal. Diantaranya aktivitas dzikir berjamaah dilakukan setiap hari sabtu kliwon berbarengan dengan kajian kitab Hikam Syaikh Ibn At-Thaillah. Zikir berjamaah dilakukan setiap ba'da shalat, sementara zikeir yā wakìl pada malam minggu, dan hari jum'at. Adapun zikir yang dilakukan pada waktu dini hari menjelang subuh merupakan rutinitas bagi santri senior. Karena waktu tersebut merupakan waktu terbukanya hijab antara seorang 'abdi/hamba dengan Allah SWT. Untuk seluruh santri sendiri, tidak diwajibkan mengamalkan amalan yā wakìl ini. Santri hanya difokuskan untuk mengaji saja, amalan dzikir yā wakil ini hanya untuk memantapkan hati saja. Selain dari amalan dzikir, di Pesantren Badrul Ulum juga diajarkan kitab-kitab tasawuf dan juga kitab-kitab tauhid seperti minhah saniyah, bugyatul auliya, albikam, dan lain sebagainya. Keilmuan masalah hati, amalnya seperti berdzikir bersama, berjamaah dalam beribadah. Sanad zikir yā wakìl ini dari Syaikh Khalil Bangkalan, Syaikh Abi Syamsiddin, Syaikh Muhammad Bahauddin al-Uwaisy, Syakih 'Abdul Qadir al-Jailani, Syaikh Abi Yazid alBustami, kesananya dari Imam AlGhazali.

Al-Qusyairi berkata, "Tempat tawakal adalah hati. Dan gerakan dengan anggota tubuh tidak bertentangan dengan tawakal dalam hati, setelah seorang hamba yakin bahwa takdir adalah kehendak Allah. Jika sesuatu sulit, maka itu adalah karena takdir-Nya. Dan jika dia sesuai (dengan keinginan kita), maka itu karena kemudahan-Nya." Al-Ghazali berkata, "Orang-orang yang bodoh menyangka bahwa syarat tawakal adalah meninggalkan usaha dan pengobatan, serta menyerah pada semua yang menghancurkan. Hal ini merupakan kesalahan, karena semua itu diharamkan oleh syariat. Syariat telah memuji tawakal dan mengharuskannya. Maka bagaimana bisa tawakal diterima jika dia berkaitan dengan hal-hal yang dilarang?" Para sufi telah menunjukkan sälik kepada sisi hati yang dalam, yaitu bahwa dalam setiap pekerjaan dia harus berusaha, tanpa bergantung pada usaha tersebut atau mencondongkan hati kepadanya. Qadhi Iyadh berkata, "Para sufi selalu menekankan pentingnya berusaha. Akan tetapi, mereka tidak membenarkan jika tawakal dibarengi dengan keberpalingan dan ketundukan terhadap usaha. Usaha tersebut merupakan sunnah Allah dan hikmah-Nya. Dan seseorang harus yakin bahwa itu tidak dapat memberi manfaat dan menolak mudarat. Akan tetapi, semuanya bersumber dari Allah" (Isa, 2005, pp. 262-263). 
Hasil internalisasi nilai tawakal pada santri di Pondok Pesantren Badrul Ulum Al-Islami terlihat dalam beberapa hal. Diantaranya orang yang sudah bertawakal akan mempunyai perasaan bahagia. Karena tawakal adalah masalah hati, jadi orang yang sudah mengamalkan yā wakìl ini akan tenang hatinya. Perubahan dari sebelum dan setelah amalan zikir ya wakìl setiap orang bisa berbeda-beda. Santri di Pesantren Badrul Ulum juga ada yang mempunyai beberapa kelebihan, diantaranya ada yang ahli dalam bidang kaligrafi, menguasai ilmu nahwu sharaf, ada yang ahli dalam bidang Grafiti, ada yang ahli dalam hal pertanian, ada santri yang ahli di bidang bangunan, ada santri yang kuat hafalannya, rajin dalam belajar dan mengaji, serta ada yang ahli di bidang Qiraat. Pondok Pesantren Badrul Ulum Al-Islami secara administrasi formal telah berjalan beberapa tahun yang lalu, dan telah meluluskan beberapa angkatan dengan cukup memuaskan, baik dari sisi pembelajaran atau dari akhlak yang ditunjukan oleh santri. Para santri berasal dari beberapa kota di Jawa Barat, Khususnya dari lingkungan sekitar bahkan ada dari luar Jawa Barat (Lampung, Jawa Timur, Medan). Dari tahun ada juga para santri yang telah meraih beberapa kejuaraan khususnya dalam event Musabaqah Tilawatil Qur'an (MTQ), baik pada tingkat lokal, nasional maupun internasional.
Ibnu Qayyim dalam Mulyana (2015: 18-19) memberikan ketentuan-ketentuan aspek tawakal sebagai berikut:

a. Memiliki keyakinan yang benar tentang kekuasaan dan kehendak Allah SWT.

b. Mengetahui hukum sebab akibat akan urusan yang dikerjakan.

c. Memperkuat qalbu dengan tauhid.

d. Menyandarkan qalbu kepada Allah dan merasa senang di sisinya.

e. Memiliki prasangka yang baik kepada Allah.

f. Menyerahkan qalbu sepenuhnya kepada-Nya dan menghalau apa saja yang merintangi.

g. Pasrah atau menyerahkan semua urusan kepada-Nya.

Hambatan internalisasi nilai tawakal pada santri di Pondok Pesantren Badrul Ulum Al-Islami diantaranya adalah belum begitu menyeluruhnya kesadaran mengenai internalisasi nilai tawakal. Jika ada seseorang yang sudah menerima ijazah zikir tetapi tidak mengamalkan zikir tersebut, maka orang tersebut bisa dikategorikan turun derajat, kalau sudah bernazar berarti berdosa. Hambatan lainnya adalah ada beberapa santri yang masih berusia sekolah seperti dari mulai tingkat SD, SMP dan SMA yang tidak melanjutkan sekolahnya. Dikhawatirkan pemahaman terhadap nilai tawakalan pun kurang optimal. Kemudian ada juga hambatan lain yakni mengenai administrasi data-data kepesantrenan. Masih kurangnya kekompakan sesama kepengurusan santri dalam rangka membantu memaksimalkan program kepesantrenan, baik penerapan punishment terhadap santri yang melanggar peraturan maupun ketegasan dalam setiap program 
internalisasi khususnya internalisasi nilai tawakal.

Hambatan dari internalisasi nilai tawakal ini sebenarnya sangat banyak sekali. Namun di Pesantren Badrul Ulum sendiri karena merupakan pesantren salaf yang juga mengadakan sekolah. Maka hambatan yang dirasapun tidak hanya dari sisi klasiknya saja tetapi juga dari dampak modernisasi global. Maka dari itu, di pesantren Badrul Ulum ini tetap diadakan pengupayaan untuk menguatkan keimanan dan meningkatkan keilmuan. Diantara riyäda untuk menuju tahap ma'rifat adalah zikir. Asal zikir adalah ash-shafa, artinya bersih dan hening. Wadahnya adalah al-wafa artinya menyempurnakan. Dan syaratnya adalah al-hudhur, artinya hadir hati sepenuhnya. Hamparannya adalah amal saleh. Dan khasiatnya adalah pembukaan dari Tuhan. Menurut bahasa, zikir artinya ingat atau sebut. (Abdullah, 2007, p. 82).

Allah menciptakan manusia dalam keadaan fitrah dalam arti berpotensi. Yaitu kelengkapan yang diberikan pada saat dilahirkan ke dunia. Potensi yang dimiliki manusia tersebut dapat dikelompokkan kepada dua hal, yaitu potensi fisik dan potensi ruhaniah. Potensi fisik adalah tubuh manusia. Proses kejadian manusia dijelaskan dalam al-Qur`ān dan Hadīìs. Diantara ayat-ayat al-Qur`ān yang mengungkapkan penciptaan manusia antara lain dalam surat alMưminūn [23] : 12-14 yang berbunyi:

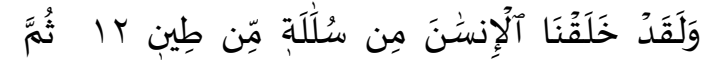

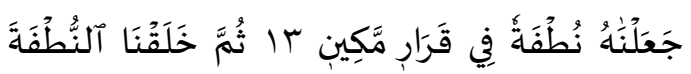

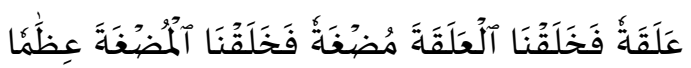

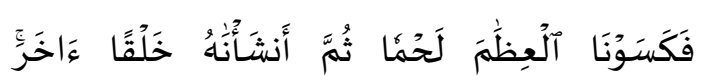

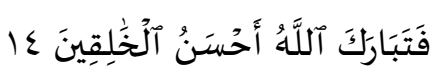
'Dan sesunggubnya Kami telah menciptakan manusia dari suatu saripati (berasal) dari tanah. Kemudian Kami jadikan saripati itu air mani (yang disimpan) dalam tempat yang kokoh (rabim). Kemudian air mani itu Kami jadikan segumpal darah, lalu segumpal darah itu Kami jadikan segumpal daging, dan segumpal daging itu Kami jadikan tulang belulang, lalu tulang belulang itu Kami bungkus dengan daging. Kemudian Kami jadikan dia makbluk yang (berbentuk) lain. Maka Maha sucilab Allah, Pencipta Yang Paling Baik"'(Q.S. alMu `minūn [23]: 12-14)

Ayat-ayat yang menerangkan tentang penciptaan manusia lebih diperjelas lagi oleh Hadīis Rasulullah SAW, antara lain:

"Sesunggubnya setiap kalian dikumpulkan kejadiannya dalam perut ibunya 40 hari dalam bentuk nutfah, kemudian dalam bentuk alaqah seperti itu (40 hari) lalu dalam bentuk mudgah seperti itu (40 hari), kemudian diutus Malaikeat kepadanya lalu Malaikat itu meniupkan rub ke dalam tububnya." (H.R. Bukhari dan Muslim)

Sedangkan potensi ruhaniah adalah akal, qalbu dan nafsu. Akal berasal dari bahasa Arab, yaitu dari kata jadian 'Aqala Ya qilu- $A$ qlan, yang secara etimologi berarti mengikat atau menahan, mengerti dan membedakan (Kosasih, 2009, pp. 9899) 


\section{PENUTUP}

Kesimpulan dari penelitian ini yaitu: (1) Tujuan internalisasi nilai tawakal pada santri di Pesantren Badrul Ulum ditekankan pada amalan zikir yō wakill, agar bertawakal. Karena tawakal itu adalah derajat keyakinan paling tinggi. Tujuan yā wakill adalah agar hati jernih (saffat asrärubu) karena setelah hati jernih seseorang akan sampai ke hadirat Ilahiyah. (2) Proses internalisasi nilai tawakal pada santri di Pesantren Badrul Ulum diantaranya diterapkan dalam beberapa hal. Yakni aktivitas dzikir berjamaah, kegiatan pengaiian, dan aktivitas keseharian. (3) Hasil internalisasi nilai tawakal pada santri di Pesantren Badrul Ulum adalah bahwa orang yang sudah bertawakal akan mempunyai perasaan bahagia. Karena tawakal adalah masalah hati, jadi orang yang sudah mengamalkan yā wakil ini akan tenang hatinya. (4) Hambatan internalisasi nilai tawakal pada santri di Pondok Pesantren Badrul Ulum diantaranya adalah belum begitu menyeluruhnya kesadaran mengenai internalisasi nilai tawakal, adanya santri takhassus di bawah usia SMA, serta kurangnya kekompakan sesama kepengurusan santri dalam rangka membantu memaksimalkan program kepesantrenan.

\section{REFERENSI}

Abdullah, M. Z. (2007). Drikir dan Tasawnf. Solo: Qaula.

Affandi, C. (2008). La Tahzan Innallaha Ma'ana Bersama Allab di Setiap Tempat dan Waktu. Bandung: Mizania.

as-Sarraj, A. N. (2002). Al-Luma' Rujukan Lengkap Ilmu Tasawuf. dari judul asli Al-Luma Lajnah Nasyr at-Turats ashShufi (Wasmukan dan Samson Rahman, Penerj.). Surabaya: Risalah Gusti.

Fahrudin. (2013). Implementasi Pendidikan

Nilai Keimanan Berbasis Tasawnf Sebagai Upaya Membentuk Karakter Manusia 'Arifun Billah di SMA Pondok Modern Sumber Daya AtTaqwa (POMOSDA) Tanjung AnomNganjuk-Jawa Timur. Bandung: (Disertasi). Sekolah Pascasarjana, Universitas Pendidikan Indonesia.

Hakam, A. (2014). K.H. Hasyim Asy'ari dan Urgensi Riyadah dalam Tasawuf Akhlaqi. Teosofi_Volume 4, Nomor 1, Juni $2014,147$.

Isa, S. '. (2005). Hakekeat Tasawnf. dari judul asli Haqäiq at-Tashawnuf (Khairul Amru Harahap, Penerj.). Jakarta: Qisthi Press.

Kosasih, A. (2009). Konsep Manusia Utuh dalam Pendidikan Umum. Ta'lim Jurnal Pendidikan Agama Islam Vol 7, No. 2, September 2009 , 98-99. Mulyana, A. (2015). Tawakal dan Kecemasan Mahasiswa pada Mata Kuliah Praktikum. Psympathic, Jurnal 
Ilmiah Psikologi Juni 2015, Vol. 2, No. 1, Hal: 17 - 24 , 18-19.

Nashihin. (2015). Internalisasi

Nilai-nilai Agama Islam dalam Pembinaan Akhlak Mulia. Jurnal Ummul Qura Vol V, No. 1, Maret 2015, 3.

Nata, A. (2003). Akblak Tasawnf. Jakarta: PT. RajaGrafindo Persada.

Ramayulis. (2011). Ilmu Pendidikan Islam. Jakarta: Kalam Mulia.

Satori, D. (2012). Metodologi Penelitian Kualitatif. Bandung: Alfabeta.

Sauri, S. (2013, February 1). Buletin Al Furqan. Bulan Rabiul Awwal Penub Makna Keteladanan, hal. 1.

Sugiyono. (2011). Metode Penelitian

Pendidikan (Pendekatan Kuantitatif, Kualitatif, dan R\$D) . Bandung: ALFABETA.

Suharto. (2011). Dari Pesantren Untuk Umat. Surabaya: Imtiyaz.

Utomo, E. P. (2016). Internalisasi Nilai-Nilai Karakter dalam Pembelajaran IPS pada Siswa SMP Negeri Model Terpadu Bojonegoro. METAFORA, Volume 2, Nomor 2, April 2016 (91-104), 95. 